\title{
Emotional Impacts of Premature Ovarian Failure in Kuwait
}

\author{
F. E. Omu ${ }^{2}$, A. A. M. El Biaa ${ }^{2}$, A. A. Ghafour ${ }^{2}$, I. T. Gadalla², A. E. $0 m u^{2,3}$ \\ ${ }^{1}$ College of Nursing, Public Authority for Applied Education \& Training, Kuwait City, Kuwait \\ ${ }^{2}$ Maternity Hospital, Kuwait City, Kuwait \\ ${ }^{3}$ Department of Obstetrics \& Gynecology, Faculty of Medicine, Kuwait University, Kuwait City, Kuwait \\ Email: "flo_omu@hotmail.com
}

Received 25 December 2015; accepted 22 February 2016; published 25 February 2016

Copyright (C) 2016 by authors and Scientific Research Publishing Inc.

This work is licensed under the Creative Commons Attribution International License (CC BY).

http://creativecommons.org/licenses/by/4.0/

(c) $\underset{\mathrm{BY}}{\mathrm{E}}$ Open Access

\section{Abstract}

Premature Ovarian Failure (POF) is cessation of ovarian functions before the age of 40 years with consequent cessation of menstruation. The objective of study was therefore to evaluate the emotional reaction and self-efficacy of women with POF. Forty-two women confirmed to have Premature Ovarian Failure seen at the outpatient clinic of Maternity Hospital fulfilled the study criteria, were enrolled into the study. Another group of 42 healthy women formed the control group. The instrument of data collection included three types of questionnaires to assess the depth of emotional reaction to the diagnosis of POF including the subjects' biodata, modified Health Orientation Scale (HOS) and Stanford Chronic Disease Self-Efficacy Scale. The women with POF presented at the clinic with infertility $(P<0.01)$, amenorrhea $(P<0.01)$ and hot flashes $(P<0.05)$. The diagnosis of ovarian insufficiency was a traumatic life event similar to bereavement (grieving of no obvious loss to others), with high level of anxiety, depression, fear of divorce, lower life satisfaction and impaired self-esteem. Fertility was generally of profound concern to all of them, because fertility was a societal landmark of womanhood and youth. The Stanford Chronic Self Efficacy scores were generally low (below 7) in coping with emotion reaction to loss of fertility, loss of menstruation, loss of self-esteem and other significant emotional reactions. The present study has demonstrated that Premature Ovarian Failure is associated with severe emotional distress and impaired ability to cope with them especially low self-esteem. A multidisciplinary management team is advocated for POF.

\section{Keywords}

Premature Ovarian Failure, Emotional Reaction, Self-Efficacy

\footnotetext{
${ }^{*}$ Corresponding author.
} 


\section{Introduction}

Premature ovarian failure (POF) (also known as hyper gonadotropic hypogonadism), premature ovarian failure, and premature menopause) involves the cessation of normal ovarian function before age 40 [1]. The condition is associated with amenorrhea, symptoms of estrogen deficiency, infertility and general health concerns. It affects approximately $1 \%$ of women by age 40 [2]. Many women with this condition experience intermittent ovarian function that may last for decades and pregnancy may occur in some women many years after the diagnosis [3]. Also used conterminously with POF is the term "primary ovarian insufficiency (POI) which was first introduced by Fuller Albright in 1942 [4]. The classic etiologies are autoimmunity, genetic factors, pelvic surgery, radiotherapy and/or chemotherapy. Although new etiologies especially genetic, have been found in the past 10 years, the cause of POF is still precisely unknown in more than $75 \%$ of cases [5].

Learning of the diagnosis of ovarian insufficiency is a traumatic life event similar to bereavement, with high level of depression, lower life satisfaction and impaired self-esteem. Loss of fertility potential was usually of profound concern [6]. Premature ovarian failure is associated with health issues such as cardiovascular disorders, osteoporosis and fracture and severe emotional distress. It has therefore become a necessity that physicians should adopt a holistic approach in patients diagnosed with premature ovarian failure, with more attention given to psychological reactions in such patients. Dealing with POF is a very emotional experience which can affect the patient's quality of life. Several investigators in this field have used the following terms to describe the emotional reactions reported by affected women on hearing of their diagnosis: devastated, depressed, shocked, confused, anxious, feeling of emptiness, loss, anger, denial, curiosity and relief to know what was wrong with them [8]-[13]. The sudden transition from being a young lady into being an old menopausal woman with all the climacteric/vasomotor symptoms and complications of estrogen deficiency such as osteoporosis and cardiovascular risks made them consider the stigma of POF to be worse than just the stigma of infertility [8]-[13]. Reactions to POF are individualized; some POF women have said they did not only experience grieving process of the "death of their dream of motherhood", but felt isolated, self-depreciation, guilty. Some women with POF confessed to feeling resentful and jealousy of fertile women [12], demonstrating a high degree of neuroticism [13].

The diagnosis of POF is associated with high level of depression, lower life satisfaction and impaired selfesteem. Fertility is generally of profound concern to most women with POF, because fertility is a societal landmark of womanhood and youth. Groff et al. [8] reported that most POF participants on their study mentioned they had communication problems with their physicians because they did not provide them with relevant information and that caused them a great deal of stress. According to Petras [7] "Knowledge is power", women with POF should be encouraged to keep abreast with research findings and new information about POF [7], and being knowledgeable will foster their sense of control [8]. Self-awareness comes with core of self-evaluation which comprises of four fundamental appraisal of oneself: self-efficacy, locus of control, self-esteem and neuroticism [14]. Orshan and Associates [15] tested the hypothesis that women with spontaneous POF differ from control women with regard to perceived social support. Investigation of the relationship between perceived social support and self-esteem showed that women with primary ovarian insufficiency had significantly lower scores than controls on the perceived social support scale and the self-esteem scale. In patients there was a significant positive correlation between self-esteem scores and perceived social support. Strategies to improve social support and selfesteem might provide a therapeutic approach to reduce the emotional suffering that accompanies the life-altering diagnosis of spontaneous primary ovarian insufficiency [15].

Self-efficacy according to Bandura [16] is the belief that a person has, regarding his/her confidence to succeed in achieving a desired outcome. Locus of control is another psychological construct which refers to the manner in which an individual perceives control over their lives and environment. People with internal locus of control have faith in their ability to achieve self-appointed objectives, and they believe that what happens to them is within their control [17]. Patients having internal locus of control maybe maladaptive in situation where the disease condition is chronic, uncontrollable/beyond their control [18]. Self-esteem is a psychological construct which describes a person's overall subjective emotional evaluation of his or her own worth [19]. In Abraham Maslow hierarch of human needs, he described self-esteem as the need for respect from others in the form of recognition, success and admiration and the need for personal self-respect in the form of self-love, self-confidence, skill or aptitude [20]. Carl Rogers, a humanistic psychologist theorized that when people have low selfesteem, they despise themselves, they believe they are worthless and incapable of being loved, subsequently leading to emotional problems [21]. "Higher self-esteem correlates with a better ability to cope with stress and a higher likeness that the individual takes on difficult tasks [22] and it is said to increase initiative and people with 
high self-esteem are more willing to act on their beliefs [23].

\subsection{Objective of Study}

To evaluate the emotional reaction of women with Premature Ovarian Failure/Primary Ovarian Insufficiency in Kuwait.

\subsection{Hypotheses}

The primary hypotheses to be tested were: 1) Compared to healthy controls, women with POF will report prior menstrual irregularity, less successful marital union, infertility and 2) More emotional affective reactions, lower levels of self-esteem, and 3) Low levels of perceived social support and self-esteem score levels.

\section{Patients and Methods}

\subsection{Study Population and Eligibility Criteria}

The study was approved by the Maternity Hospital, Kuwait, Institutional Review Board.

We recruited women with spontaneous 46, XX Premature Ovarian Failure that were seen at the General Outpatient and Infertility clinics of Maternity Hospital, Kuwait. The eligibility criteria included:

1. Women with previously known ovarian function and were previously menstruating

2. Women previously healthy and active

3. Women with cessation of menstruation for at least $4-6$ months

4. Hormone profile revealed high FSH ( $\geq 40 \mathrm{IU} / \mathrm{L})$, high LH ( $\geq 28 \mathrm{IU} / \mathrm{L}$ and low estradiol $(\leq 100 \mathrm{pmol} / \mathrm{L})$ and Anti-Mullerian Hormone $(\leq 4.8 \mathrm{mg} / \mathrm{L})$.

1) Exclusion criteria

Women with Premature Ovarian Failure/primary ovarian insufficiency as a result of surgery, radiation, chemotherapy, or known karyotype abnormalities were not included.

2) Controls

Control women were recruited from the gynae outpatient Clinic.

1. They were between the ages of 18 and 39 years,

2. Healthy, free of chronic disease, not pregnant,

3. Regularly menstruating (cycles between 22 and 35 days).

Patients and controls were recruited concurrently and matched for demographic characteristic of age only.

3) Ethical considerations

The Institutional Review Board of the Maternity Hospital, Kuwait approved the study. Verbal informed consent was obtained from all participants.

4) Clinical Evaluation

Prior menstrual irregularity and amenorrhea of at least 4 - 6 months (as detailed in Questionnaire 1) associated with two serum FSH levels in the menopausal range (FSH $\geq 40 \mathrm{IU} / \mathrm{L}$ were required for diagnosis of Premature Ovarian Failure 1.

5) Interviews

All interviews were conducted between September 2010 and August 2015 when the patients attended the clinic for consultation either on referral from the polyclinic or direct referral by colleagues, after establishing eligibility for this study. This was certainly based on the informant's willingness to participate in the study and her ability to converse in English or Arabic languages. In a few cases, translators were sought for when the patient spoke any other language. Although the setting was in the combined infertility clinic, the women were interviewed without their husbands before seeing the medical team. The interviews in languages other than English language were taped, transcribed and translated into English. Patients who were eligible were given three questionnaires.

\subsection{Instruments for Data Collection}

Questionnaire No. 1: This include the biodata of each women with POF in five sections:

(A) General Data, (B) Lifestyle, (C) OB-GYN History, (D) Past Medical History, and (E) Comprehensive Physical Examination. The age, marital and educational status and occupation including that of the husband, and smoking (cigarette and sheesha) and alcohol consumption habits were documented. The obstetric and gyneco- 
logical history included pubertal developmental milestones especially age at menarche and other sexual characteristics and menstrual history including cyclicity and any abnormality especially oligomenorrhea and amenorrhea with hot flushes and night sweats and parity and mode of delivery and outcome and infertility were collated. Any medical and surgical disorder or intervention were documented. Physical examination included blood pressure, body mass index (BMI) and full system evaluation.

Questionnaire No. 2: This questionnaire was designed internally in the infertility unit but mainly derived from the Health Orientation Scale (HOS) (Snell et al. 1991). This is a short, reliable, and easily used instrument to determine the intensity of the participant bodily fatigue. Higher scores indicate a higher intensity of affective emotional reaction.

The scale we used consists of 15 questions aimed at obtaining subjective information regarding emotional reactions. The affective reactions to POF included fear of childlessness, anxiety, depression, worry about possibility of divorce and loneliness especially if they remain single or divorced. Other emotional concerns evaluated with this scale include grief, poor concentration, labile moods, aggression, irritability and fatigue.

We used the scale derived from the Health Orientation Scale (HOS) to assess the psychological reaction of women to a diagnosis of Premature Ovarian Failure (POF).

Instructions to participants/respondents

The items listed below refer to people's reaction to the diagnosis of premature Ovarian Failure. Please read each item carefully and decide to what extent it is characteristic of you. Give each item a rating of how much it applies to you by using the following scale:

1) $=$ Not at all characteristic of me.

2) = Slightly characteristic of me.

3) =Somewhat characteristic of me.

4) = Moderately characteristic of me.

5) =Very characteristic of me. (see Appendix 1)

Questionnaire 3. Stanford Chronic Disease Self-Efficacy Scale was used to assess how the women with premature ovarian failure coped with Emotional reactions. These scales were developed and tested for the Chronic Disease Self-Management study. The 6-item scale contains items taken from several self-efficiency scales developed for the Chronic Disease Self-Management study [24]. The 6 item scale is the one used in the present study because it is much less burdensome for participating subjects. It covers several domains that are common across many chronic diseases, symptom control, role function, emotional functioning and communicating with physicians. The rationale is to have an idea how confident the patient is in doing certain activities or coping with certain emotional affective reactions. The scoring is done for each item is the number circled. The score for the scale is the mean of the six items. If more than two items are missing, do not score the scale. Higher number indicates higher self-efficacy. Possible scores range from zero (low coping ability) to ten (high coping) [24].

For example (see Appendix 2)

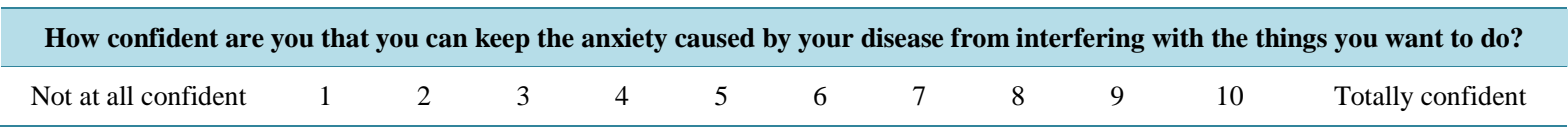

\subsection{Statistical Methods}

We analyzed fully completed questionnaires only. We tested comparisons with the Wilcoxon Rank Sum, proportions by Chi Square, and correlations with the Spearman Rank Order. We report results as mean (SD) or median (range). The correlation among variables in each set of emotional reaction to POF was calculated using the Spearman and Pearson lineal correlation coefficients, respectively (significant correlation was considered at significance level $<0.05$ ).

\section{Results}

As shown in Table 1, 42 women between 20 and 39 years with mean age of $28 \pm 4.2$ years and with diagnosis of Premature Ovarian Failure were interviewed and compared to a healthy control group of 42 women, matched for age and parity with the study group.

The POF study group was significantly associated with spinsterhood and divorce $(P<0.05)$. Similarly, more women with POF had only primary education $(P<0.05)$. The main reasons for the clinic consultation included 
Table 1. Characteristics of patients with premature ovarian failure.

\begin{tabular}{|c|c|c|c|c|}
\hline & Variables & POF N = $42(\%)$ & Healthy Women N = 42 (\%) & $P$ value \\
\hline 1. & $\begin{array}{c}\frac{\text { Age (years) }}{20-29} \\
30-39\end{array}$ & $\begin{array}{l}19(45.2) \\
23(54.8)\end{array}$ & $\begin{array}{l}18(42.9) \\
24(57.1)\end{array}$ & $\begin{array}{l}\text { NS } \\
\text { NS }\end{array}$ \\
\hline 2 & $\begin{array}{c}\text { Marital Status } \\
\text { Single } \\
\text { Married } \\
\text { Divorced }\end{array}$ & $\begin{array}{l}13(30.9) \\
19(45.2) \\
10(23.8)\end{array}$ & $\begin{array}{c}4(9.5) \\
35(83.3) \\
3(7.1)\end{array}$ & $\begin{array}{l}0.05 \\
0.05 \\
0.05\end{array}$ \\
\hline 3 & $\begin{array}{l}\frac{\text { Education }}{\text { Primary }} \\
\text { Secondary } \\
\text { University }\end{array}$ & $\begin{array}{c}8(19.1) \\
26(61.9) \\
8(19.1)\end{array}$ & $\begin{array}{c}3(7.1) \\
22(52.4) \\
17(40.5)\end{array}$ & $\begin{array}{c}0.05 \\
0.9 \\
0.05\end{array}$ \\
\hline 4 & $\begin{array}{c}\frac{\text { Parity }}{0} \\
1-3\end{array}$ & $\begin{array}{l}26(61.9) \\
16(38.1)\end{array}$ & $\begin{array}{c}6(14.3) \\
36(64.3)\end{array}$ & $\begin{array}{l}0.01 \\
0.05\end{array}$ \\
\hline 5 & $\begin{array}{c}\text { Presenting Symptoms } \\
\text { Oligomenorrhea } \\
\text { Infertility } \\
\text { Primary } \\
\text { Secondary } \\
\text { Hot Flashes } \\
\text { Night Sweats }\end{array}$ & $\begin{array}{l}34 \quad(81.0) \\
31(73.8) \\
15(37.5) \\
16(38.1) \\
30(71.4) \\
23(54.8)\end{array}$ & $\begin{array}{l}6(14.3) \\
9(21.4) \\
3(7.1) \\
6(14.3) \\
3(7.1) \\
4(9.5)\end{array}$ & $\begin{array}{l}0.01 \\
0.05 \\
0.05 \\
0.05 \\
0.01 \\
0.05\end{array}$ \\
\hline
\end{tabular}

presenting symptoms included oligomenorrhoea (81\%), infertility (74\%), uncomfortable hot flashes (71\%) and night sweats (55\%) and dyspareunia like women at natural menopause. The diagnosis was discussed with them after the results of their hormone profile. All the women admitted that all these conditions gave them tremendous distress.

Table 2 is a summary of the reaction of the women on hearing that they have POF. In other to assess the magnitude of the problem they face, their reactions were compared with those of healthy women.

The items on the anxiety subscale refer to anxious feelings associated with the status of one's health. More directly, these items were designed to emphasize the patient's feelings of tension, discomfort and anxiety about their physical health and consequences of premature ovarian failure. People who endorse these items are those who experience chronic anxiety as a result of thinking about their physical health and consequences of premature ovarian failure. Fear of childlessness or loss of fertility and associated anxiety alternating with depression were more common in women with premature ovarian failure compared to control $(P<0.01)$.

Table 3 is used to emphasize the degree of reactions to test the hypothesis that women with POF having life shattering conditions that affect their self-esteem.

Although depression set in later, it was quite significant, with the concern of possibility of the husband asking for divorce and marrying a younger and healthy wife $(P<0.05)$. Fear of loneliness, grief and poor concentration were also common. About $43 \%$ of the women felt guilty and regretted not getting married earlier when they were having regular menstrual periods. About a third of the women had labile mood. One of the graduates with POF described it as having bipolar nature. Another woman threatened to kill herself and the husband if the latter tried to marry another woman. During the study period, there were three single women who became engaged but had no intention of divulging the nature of their fertility potential to their fiances.

Using the Spearman's coefficient, loss of fertility, anxiety, depression, concerns and fear of divorce and poor concentration were all expressed significantly high levels and ultimately lead to loss of self-esteem.

Majority of the patients in this study identified the following ten major reactions when they were diagnosed with POI: anxiety, depression, anger, fear of divorce, loss of self-esteem, loss of femininity and youth, loss of ability to have children, fear of disease, loss of social contacts, problem of communication with physician and family. Table 3 shows the composite scores of coping with emotional reactions to Premature Ovarian Failure. The scores were significant loss of fertility potential, loss of menstruation and consequent illness, depression and anger.

Thematic analysis of emotional reaction was done providing relevant themes for the adaptation of the Stanford Chronic Disease Self-Efficacy Scale [24]. The scale consists of 6 items and each is scored ranging from 1 10, where 1 means not at all confident and 10 means totally confident. The format for the Stanford Chronic Disease Self-Efficacy Scale for coping with depression is shown in Table 4. The items on the loss of menstruation, 
Table 2. Emotional affective reactions to premature ovarian failure.

\begin{tabular}{cccc}
\hline Variables & POF Women Number $=42$ & Healthy Women Number $=42$ & P value \\
\hline Fear of Childlessness & $31(73.8)$ & $5(11.9)$ & 0.01 \\
Anxiety & $31(73.8)$ & $7(16.7)$ & 0.01 \\
Depression & $28(66.7)$ & $8(19.1)$ & 0.05 \\
Worry of Divorce & $28(66.7)$ & $4(9.5)$ & 0.05 \\
Loneliness & $24(57.1)$ & $8(19.1)$ & 0.05 \\
Grief & $18(42.9)$ & $7(16.7)$ & 0.05 \\
Poor Concentration & $18(42.9)$ & $6(14.3)$ & 0.05 \\
Guilt & $18(42.9)$ & $4(9.5)$ & 0.05 \\
Regret & $15(35.7)$ & $2(4.8)$ & 0.05 \\
Labile Moods & $14(33.3)$ & $2(4.8)$ & 0.05 \\
Aggression & $12(28.6)$ & $3(7.1)$ & NS \\
Irritability & $12(28.6)$ & $4(9.5)$ & NS \\
Fatigue & $8(19.1)$ & $3(7.1)$ & \\
\hline
\end{tabular}

Table 3. Spearman correlation coefficients among emotional reactions.

\begin{tabular}{|c|c|c|c|c|c|c|c|c|c|c|}
\hline & 1 & 2 & 3 & 4 & 5 & 6 & 7 & 8 & 9 & 10 \\
\hline 1 & 0.864 & & & & & & & & & \\
\hline 2 & 0.654 & 0.782 & & & & & & & & \\
\hline 3 & 0.722 & 0.544 & 0.434 & & & & & & & \\
\hline 4 & 0.824 & 0.648 & 0.564 & 0.446 & & & & & & \\
\hline 5 & 0.242 & 0.123 & 0.112 & 0.084 & 0.224 & & & & & \\
\hline 6 & 0.446 & 0.432 & 0.242 & 0.118 & 0.246 & 0.224 & & & & \\
\hline 7 & 0.126 & 0.065 & 0.212 & 0.216 & 0.128 & 0.084 & 0.242 & & & \\
\hline 8 & 0.548 & 0.128 & 0.126 & 0.234 & 0.098 & 0.324 & 0.222 & 0.118 & & \\
\hline 9 & 0.476 & 0.562 & 0.128 & 0.234 & 0.224 & 0.442 & 0.466 & 0.322 & 0.234 & \\
\hline 10 & 0.642 & 0.484 & 0.568 & 0.436 & 0.464 & 0.542 & 0.442 & 0.543 & 0.646 & 0.454 \\
\hline
\end{tabular}

1 = Fear of Childlessness. $2=$ Anxiety. $3=$ Depression. 4 = Worry of divorce. $5=$ =Loneliness. $6=$ Grief. $7=$ Poor concentration. $8=$ Guilt. $9=$ Regret. $10=$ Aggression. "Spearman's coefficient $\geq 0.300 P<0.05$.

Table 4. Emotional composite scores of coping with emotional reactions to premature ovarian failure.

\begin{tabular}{cccccccc}
\hline Variable & No of Subjects & No of Items & Scale range & Mean & $\begin{array}{c}\text { Standard } \\
\text { deviation }\end{array}$ & $\begin{array}{c}\text { Internal Const. } \\
\text { reliability }\end{array}$ & $\begin{array}{c}\text { Retest } \\
\text { Reliability }\end{array}$ \\
\hline Anxiety & 42 & 3 & $1-10$ & 8.72 & 1.40 & 0.64 & 0.72 \\
Depression & 42 & 6 & $1-10$ & 5.28 & 2.12 & 0.74 & 0.78 \\
Anger & 42 & 4 & $1-10$ & 4.64 & 2.20 & 0.72 & 0.68 \\
Fear of Divorce & 42 & 2 & $1-10$ & 7.24 & 1.80 & 0.78 & 0.80 \\
Loss of self esteem & 42 & 2 & $1-10$ & 6.44 & 2.24 & 0.72 & 0.68 \\
Loss of Social contacts & 42 & 3 & $1-10$ & 4.32 & 1.60 & 0.74 & 0.78 \\
Loss of Menstruation & 42 & 5 & $1-10$ & 6.22 & 1.28 & 0.78 & 0.76 \\
Loss of fertility & 42 & 3 & $1-10$ & 6.48 & 2.48 & 0.82 & 0.84 \\
Communication with Physician & 42 & 3 & $1-10$ & 7.48 & 2.82 & 0.72 & 0.72 \\
Obtain help from close relatives & 42 & 2 & $1-10$ & 6.22 & 2.62 & 0.72 & 0.82 \\
\hline
\end{tabular}


fear of divorce, Self esteem, and obtaining help subscale measure the extent to which people derive a sense of esteem from their affective reaction, and the extent to which they feel confident about their diagnosis of premature ovarian failure. More specifically, these items are concerned with how positive individuals feel about their physical wellness. People who endorse these items are those who feel good about the health status of their bodies; they feel positive esteem about their health and they have an air of confidence that their health is robust and durable.

Apart from anxiety, all the coping scores were low at about 7 and below, thus showing they were unable to cope with loss of self-esteem, loss of fertility, menstruation and other associated disorders, such as ability to seek help from close relative and with ability to communicate with their physician are issues in which they have coping impairment

\section{Discussion}

The present study has demonstrated that emotional reaction to the diagnosis of POF is common in Kuwait. Majority of the patients in the present study identified the following ten major reactions when they were diagnosed with POI: anxiety, depression, anger, fear of divorce, loss of self-esteem, loss of femininity and youth, loss of ability to have children, fear of disease, loss of social contacts, problem of communication with physician and family. These reactions are similar to those reported by Mann et al. [10]. Evidently, women with Premature Ovarian Failure in the present study, are high on neuroticism. Neuroticism is operationally defined by items referring to irritability, anger, sadness, anxiety, worry, hostility, self-consciousness, and vulnerability that have been found to be substantially correlated with one another in factor analyses. For individuals who are high on neuroticism, such negative emotional responses to challenges are both frequent and out of proportion to the circumstances. In addition, persons high in neuroticism are often self-critical, sensitive to the criticism of others, and exhibit the personality trait to respond with negative emotions to threats, frustration and loss [13]. With the strong association between POF and psychological distress, particularly neuroticism, the suggestion that psychological care should be included in the overall management of POF [15] is appropriate. Hearing the news of the diagnosis has been described as similar to learning about a death in the family. In the Stanford Chronic Disease Self-Efficacy Scale [24] used in the present study, apart from anxiety, all the coping scores were low at about 7 and below, thus showing they were unable to cope with loss of self-esteem, loss of fertility, menstruation and other associated disorders. Emotional aspect of POF was reported in a study by Groff et al. [8]. The median age of the women with premature ovarian failure was 28 years at diagnosis, as in the present study. Overall, 71\% were unsatisfied with the manner in which they were informed by their clinician, and 89\% reported experiencing moderate to severe emotional distress at the time. In this study, Stanford Chronic Disease Self-Efficacy Scales have shown that women with premature ovarian failure have serious emotional reaction which they are not able to cope with. There is evidence that coping is activated by a greater degree of distress that is consistent with accepted stress and coping theories. For example, higher self-esteem is associated with lower infertility stress [15] [25]. Expectations of personal efficacy are based on four major sources of information: performance accomplishments, vicarious experience, verbal persuasion and physiological state. During treatment POF women can through modeling and guided performance learn generalized skills for dealing successfully with stressful situations [16]. These skills will enable them to overcome varied dysfunctional fears and increase their self-efficacy in difficult situation. Functional well-being in women with POF is positively correlated with spiritual well-being [12] [26]. In general successful adaptation to fear of divorce, loss of self-esteem, loss of femininity and youth, loss of ability to have children, fear of disease and loss of social contacts are related to the extent to which the loss has been correctly anticipated, available support and opportunities and resources to address them [27].

The present study did not evaluate strategies of intervention to ameliorate the emotional reaction to POF. An integrated approach to the management of POF as advocated by the National Institute of Health on POF [28] should be adopted. The first imperative after making the diagnosis of spontaneous Premature Ovarian Failure (POF) is to inform the patient of the diagnosis in a most caring manner, provide accurate information, and offer referral to appropriate resources for emotional support [8]. Pharmacotherapy in form of Estrogen replacement therapy is useful to abort climacteric symptoms like hot flushes and night sweat and as prophylaxis against long term health consequences such as osteoporosis and cardiovascular disorders [29]. Groff et al. [8] reported that most POF participants on their study mentioned they had communication problems with their physicians because they did not provide them with relevant information and that caused them a great deal of stress. Express- 
ing feeling to confidants, relatives and friends and colleague and people with similar problem. Openness was positively associated with problem-solving. In addition, results indicated that an individual who appraised his or her marital difficulties as threatening, compared to his or her resources, was more likely to use distancing/ avoidance as coping strategy [30]. Women with POF should be encouraged to gather information about the disorder. Knowledge is power [7]. The patients therefore keep abreast with research findings and new information about POF [7] through reading and talking to their doctors, counsellors and support groups.

The patient should be counselled about self-care and validation of her feelings and confirm self-worth and reduce low self-esteem [31]. A sedentary, inactive lifestyle does not promote an environment with which to naturally cleanse the body of excess hormones and toxins. Exercise gets the hearts beating faster which in turn pumps more fresh oxygenated blood to the entire body. Women with POF have many concerns. Therefore, the physician or counsellor has the onerous responsibility to educate her to help allay or reduce the fears of divorce and fertility and discuss solutions tailored to the circumstances of the individual woman [25]. It is mandatory to determine what options are available. The options include waiting for spontaneous conception, Child-free living, Adoption, Foster children, Oocyte donation and Embryo donation [32].

Rafique and research team [12] now include a reproductive endocrinologist, reproductive psychiatrist, medical endocrinologist, occupational therapist, recreational therapist, nutritionist, chaplain, and social worker in the management team. The chaplain on the research team provides spiritual care. Evidently, POF women who scored highly on the measures of spiritual well-being also scored better on the measures of functional well-being, probably as a result of their rearranging their goals and finding strength in spiritual care that infuses them with positive energy to persevere in the treatment of POI [12] [26].

\section{Limitations of the Study}

1. A major limitation of this study is the small sample size. In future it will be commendable to study a large number of women with premature ovarian failure through a multicenter study design.

2. There was no intervention in the present study. Evaluation of the role of spirituality through the inclusion of Islam and Christianity will be of clinical interest.

\section{Conclusion}

Premature Ovarian Failure is associated with severe emotional reactions and pose significant psychological difficulty for a sizeable proportion of those who have the condition, with impaired ability to cope with their low self-esteem. Management should involve a multi-disciplinary and holistic approach in which the provision of psychological care should be an integral part of clinical management. Affected women need an effective support system to help them come to terms with their diagnosis.

\section{Conflict of Interest}

The authors declare no conflict of interest in the present study.

\section{References}

[1] Omu, A.E. and Al-Qattan, N. (1996) Premature Menopause. Singapore Journal of Obstetrics and Gynaecology, 27, 23-28.

[2] Conway, G.S. (1997) Premature Ovarian Failure. Current Opinion in Obstetrics and Gynecology, 9, 202-206. http://dx.doi.org/10.1097/00001703-199706000-00012

[3] Check, J.H. and Katsoff (2006) Successful Pregnancy with Spontaneous Ovulation in a Woman with Apparent Premature Ovarian Failure Who Failed to Conceive Despite Four Transfers of Embryos Derived from Donated Oocytes. Clinical and Experimental Obstetrics and Gynecology, 33, 13-15.

[4] Nelson, L.M. (2009) Primary Ovarian Insufficiency. NEJM, 360, 606-614. http://dx.doi.org/10.1056/NEJMcp0808697

[5] Christin-Maitre, S. and Braham, R. (2008) General Mechanisms of Premature Ovarian Failure and Clinical Check-Up. Gynécologie Obstétrique \& Fertilité, 36, 857-861. http://dx.doi.org/10.1016/j.gyobfe.2008.07.003

[6] Artini, P.G., Ruggiero, M., Uccelli, A., Obino, M.E. and Cela, V. (2013) Fertility Management of Patients with Reduced Ovarian Reserve. Reproductive System \& Sexual Disorders, 5.

[7] Petras, K. (1999) The Premature Menopause Book: When the Change of Life Comes Too Early. HarperCollins, New 
York.

[8] Groff, A.A., Covington, S.N., Halverson, L.R., Fitzgerald, O.R., Vanderhoof, V., Calis, K. and Nelson, L.M. (2005) Assessing the Emotional Needs of Women with Spontaneous Premature Ovarian Failure. Fertility and Sterility, 83, 1734-1741. http://dx.doi.org/10.1016/j.fertnstert.2004.11.067

[9] De Angelo, D. (2000) Sudden Menopause: Restoring Health and Emotional Well-Being. Hunter House, Salt Lake City.

[10] Mann, E., Singer, D., Pitkin, J. and Panay Nand Hunter, M.S. (2012) Psychological Adjustment in Women with Premature Ovarian Failure. Climacteric, 15, 481-489. http://dx.doi.org/10.3109/13697137.2011.647841

[11] Sterling, E.W. and Nelson, L.M. (2011) From Victim to Survivor to Thriver: Helping Women with Primary Ovarian Insufficiency Integrate Recovery, Self-Management, and Wellness. Seminars in Reproductive Medicine, 29, 353-361. http://dx.doi.org/10.1055/s-0031-1280920

[12] Rafique, S., Sterling, E.W. and Nelson, L.M. (2012) A New Approach to Primary Ovarian Insufficiency. Obstetrics \& Gynecology Clinics of North America, 39, 567-586. http://dx.doi.org/10.1016/j.ogc.2012.09.007

[13] Lahey, B.B. (2009) Public Health Significance of Neuroticism. American Psychologist, 64, 241-256. http://dx.doi.org/10.1037/a0015309

[14] Judge, T.A., Locke, E.A. and Durham, C.C. (1997) The Dispositional Causes of Job Satisfaction: A Core Evaluations Approach. Research in Organizational Behavior, 19, 151-188.

[15] Orshan, S.A., Ventura, J.L., Covington, S.N., Vanderhoof, V.H., Troendle, J.F. and Nelson, L.M. (2009) Women with Spontaneous 46, XX Primary Ovarian Insufficiency (Hypergonadotropic Hypogonadism) Have Lower Perceived Social Support than Control Women. Fertility and Sterility, 92, 688-693. http://dx.doi.org/10.1016/j.fertnstert.2008.07.1718

[16] Bandura, A. (1977) Self-Efficacy: Towards a Unifying Theory of Behavioral Change. Psychological Review, 84, 191-215. http://dx.doi.org/10.1037/0033-295X.84.2.191

[17] Klein, J. and Wasserstein-Warnet, M. (1999) Predictive Validity of the Locus of Control Test in Selection of School Administrators. Journal of Educational Administrators, 38, 7-24. http://dx.doi.org/10.1108/09578230010310957

[18] Burish, T.G., Carey, M.P., Wallston, K.A., Stein, M.J., Jamison, R.N. and Lyles, J.N. (1984) Health Locus of Control and Chronic Disease: An External Orientation May Be Advantageous. Journal of Social and Clinical Psychology, 2, 326-332. http://dx.doi.org/10.1521/jscp.1984.2.4.326

[19] Smith, E.R. and Mackie, D.M. (2007) Social Psychology. 3rd Edition, Psychology Press, Hove.

[20] Cianci, R. and Gambrel, P.A. (2003) Maslow's Hierarchy of Needs: Does It Apply in a Collectivist Culture. Journal of Applied Management and Entrepreneurship, 8, 143-161.

[21] Wickman, S.A. and Campbell, C. (2003) An Analysis of How Carl Rogers Enacted Client-Centered Conversation with Gloria. Journal of Counseling \& Development, 81, 178-184. http://dx.doi.org/10.1002/j.1556-6678.2003.tb00239.x

[22] Schacter, D.L., Gilbert, D.T. and Wegner, D.M. (2009) Self Esteem. In: Schacter, D.L., Gilbert, D.T. and Wegner, D.M., Eds., Psychology, 2nd Edition, Barnes \& Noble, Worth Publishers, New York.

[23] Snell, W.E., Johnson, G., Lloyd, P.J. and Hoover, M.W. (1991) The Health Orientation Scale: A Measure of Psychological Tendencies Associated with Health. European Journal of Personality, 5, 169-183. http://dx.doi.org/10.1002/per.2410050208

[24] Stanford Chronic Disease Self-Management Study. Psychometrics Reported in: Lorig, K., Stewart, A., Ritter, P., González, V., Laurent, D. and Lynch, J. (1996) Outcome Measures for Health Education and Other Health Care Interventions. Sage Publications, Thousand Oaks, 24-25, 41-45.

[25] Davis, M., Ventura, J.L., Wieners, M., Covington, S.N., Vanderhoof, V.H. and Ryan, M.E. (2010) The Psychosocial Transition Associated with Spontaneous 46, XX Primary Ovarian Insufficiency: Illness Uncertainty, Stigma, Goal Flexibility, and Purpose in Life as Factors in Emotional Health. Fertility and Sterility, 93, 2321-2329. http://dx.doi.org/10.1016/j.fertnstert.2008.12.122

[26] Ventura, J.L., Fitzgerald, O.R., Koziol, D.E., Deloris, E., et al. (2007) Functional Well-Being Is Positively Correlated with Spiritual Well-Being in Women Who Have Spontaneous Premature Ovarian Failure. Fertility and Sterility, 87, 584-590. http://dx.doi.org/10.1016/j.fertnstert.2006.07.1523

[27] Parkes, C. (1988) Bereavement as a Psychosocial Transition: Process of Adaptation to Change. Journal of Social Issues, 44, 53-65. http://dx.doi.org/10.1111/j.1540-4560.1988.tb02076.x

[28] Cooper, A.R., Baker, V.L., Sterling, E.W., Ryan, M.E., Woodruff, T.K. and Nelson, L.M. (2011) The Time Is Now for a New Approach to Primary Ovarian Insufficiency. Fertility and Sterility, 95, 1890-1897.

http://dx.doi.org/10.1016/j.fertnstert.2010.01.016

[29] Shuster, L.T., Rhodes, D.J., Gostout, B.S., Grossardt, B.R. and Rocca, W.A. (2010) Premature Menopause or Early 
Menopause: Long-Term Health Consequences. Maturitas, 65, 161-165. http://dx.doi.org/10.1016/j.maturitas.2009.08.003

[30] Bouchard, G. (2003) Cognitive Appraisals, Neuroticism, and Openness as Correlates of Coping Strategies: An Integrative Model of Adaptation to Marital Difficulties. Canadian Journal of Behavioural Science, 35, 1-12. http://dx.doi.org/10.1037/h0087181

[31] Liao, K.L., Wood, N. and Conway, G.S. (2000) Premature Menopause and Psychological Well-Being. Journal of Psychosomatic Obstetrics \& Gynecology, 21, 167-174. http://dx.doi.org/10.3109/01674820009075624

[32] Baker, V. (2011) Life Plans and Family-Building Options for Women with Primary Ovarian Insufficiency. Seminars in Reproductive Medicine, 29, 362-367. http://dx.doi.org/10.1055/s-0031-1280921 


\section{Appendix 1}

Scale 2.

HEALTH ORIENTATION SCALE (HOS)

INSTRUCTIONS: The items listed below refer to people's health. Please read each item carefully and decide to what extent it is characteristic of you. Give each item a rating of how much it applies to you by using the following scale:

$A=$ Not at all characteristic of me.

$\mathrm{B}=$ Slightly characteristic of me.

$\mathrm{C}=$ Somewhat characteristic of me.

$\mathrm{D}=$ Moderately characteristic of me.

$\mathrm{E}=$ Very characteristic of me.

NOTE:

Remember to respond to all items, even if you are not completely sure.

Your answers will be kept in the strictest confidence.

Also, please be honest in responding to these statements.

1. I am very aware of how healthy my body feels.

2. I sometimes wonder what others think of my physical health.

3. I feel anxious when I think about my health.

4. I feel confident about the status of my health.

5. I do things that keep me from becoming physically unhealthy.

6. I'm very motivated to be physically healthy.

7. I feel like my physical health is something that I myself am in charge of.

8. The status of my physical health is determined mostly by chance happenings.

9. I expect that my health will be excellent in the future.

10. I am in good physical health.

11. I notice immediately when my body doesn't feel healthy.

12. I'm very concerned with how others evaluate my physical health.

13. I'm worried about how healthy my body is.

14. I rarely become discouraged about my health.

15. I am motivated to keep myself from becoming physically unhealthy.

16. I'm strongly motivated to devote time and effort to my physical health.

17. My health is something that I alone am responsible for.

18. The status of my physical health is controlled by accidental happenings.

19. I believe that the future status of my physical health will be positive.

20. My body is in good physical shape.

21. I'm sensitive to internal bodily cues about my health.

22. I'm very aware of what others think of my physical health.

23. Thinking about my health leaves me with an uneasy feeling.

24. I am pleased with how well and healthy I feel.

25. I try to avoid engaging in behaviors that undermine my physical health.

26. I have a strong desire to keep myself physically healthy.

27. The status of my physical health is determined largely by what I do (and don't do).

28. Being in good physical health is just a matter of luck.

29. I do not expect to suffer health problems in the future.

30. I am a well-exercised person.

31. I know immediately when I'm not feeling in great health.

32. I'm concerned about how my physical health appears to others.

33. I usually worry about whether I am in good health.

34. I have positive feeling about my health.

35. I really want to prevent myself from getting out of shape.

36. It's really important to me that I keep myself in proper physical health.

37. What happens to my physical health is my own doing.

38. Being in excellent physical shape has little or nothing to do with luck. 
39. I will probably experience a number of health problems in the future.

40. My body needs a lot of work in be in excellent physical shape.

41. I'm very aware of changes in my physical health.

42. I'm concerned about what other people think of my physical health.

43. I feel nervous when I think about the status of my physical health.

44. I feel that I have handled my health very well.

45. I am really motivated to avoid being in terrible physical shape.

46. I strive to keep myself in tip-top physical shape.

47. Being in good physical health is a matter of my own ability and effort.

48. I don't believe that chance or luck play any role in the status of my physical health.

49. I anticipate that my physical health will deteriorate in the future.

50. My physical health is in need of attention.

\section{Copyright-1996}

\section{Scoring Instructions for the Health Orientation Scale (HOS)}

The Health Orientation Scale (HOS) consists of10 health-oriented subscales, each containing five items.

The labels, descriptions, and items for each of these subscales are listed below:

1. Personal Health Consciousness: The items on the Personal Health Consciousness (PHC) subscale refer to an awareness of one's health. These items were designed to measure people's tendency to think about and to reflect about their health. People who endorse these items are those who think about that status of their physical health, and who in general are reflective about the nature of the health and wellness of their body.

1. I am very aware of how healthy my body feels.

11. I notice immediately when my body doesn't feel healthy.

21. I'm sensitive to internal bodily cues about my health.

31. I know immediately when I'm not feeling in great health.

41. I'm very aware of changes in my physical health.

2. Health Image Concern: The items on the Health Image Concern (HIC) subscale refer to an awareness of other people's reactions to one's health. More specifically, these items were designed to measure people's public concern about the image which their health (or lack thereof) projects to others. People who endorse these items are those who are concerned about the appearance of their health to others, the impression their health makes on others, and how healthy and well others consider them to be.

2. I sometimes wonder what others think of my physical health.

12. I'm very concerned with how others evaluate my physical health.

22. I'm very aware of what others think of my physical health.

32. I'm concerned about how my physical health appears to others.

42. I'm concerned about what other people think of my physical health.

3. Health Anxiety: The items on the Health Anxiety (HA) subscale refer to anxious feelings associated with the status of one's health. More specifically, these items were designed to tap people's feelings of tension, discomfort and anxiety about their physical health. People who endorse these items are those who experience chronic anxiety as a result of thinking about their physical health.

3. I feel anxious when I think about my health.

13. I'm worried about how healthy my body is.

23. Thinking about my health leaves me with an uneasy feeling.

33. I usually worry about whether I am in good health.

43. I feel nervous when I think about the status of my physical health.

4. Health-Esteem and Confidence: The items on the Health-Esteem and Confidence (HEC) subscale were designed to measure the extent to which people derive a sense of esteem from the physical status of their body, and the extent to which they feel confident about their physical health. More specifically, these items are concerned with how positive individuals feel about their physical wellness. People who endorse these items are those who feel good about the health status of their bodies; they feel positive esteem about their health and they have an air of confidence that their health is robust and durable.

4. I feel confident about the status of my health.

14. I rarely become discouraged about my health. (R)

24. I am pleased with how well and healthy I feel. 
34. I have positive feeling about my health.

44. I feel that I have handled my health very well.

5. Motivation to Avoid Unhealthiness: The items on the Motivation to Avoid Unhealthiness (MAU) subscale refer to motivational tendency to avoid being or becoming unhealthy. More specifically, these items were designed to measure people's motivational tendency to avoid poor physical health. People who endorse these items are those who are concerned about becoming unhealthy; they are motivated to avoid behaviors and activities which undermine their physical health.

5. I do things that keep me from becoming physically unhealthy.

15. I am motivated to keep myself from becoming physically unhealthy.

25. I try to avoid engaging in behaviors that undermine my physical health.

35. I really want to prevent myself from getting out of shape.

45. I am really motivated to avoid being in terrible physical shape.

6. Motivation for Healthiness: The items on the Motivation for Healthiness (MFH) subscale refer to the motivation to pursue positive physical health. More specifically, these items were designed to measure people's motivation to keep in excellent physical health. People who endorse these items are those who are motivated to attend to the physical health of their body, to engage in activities which promote their physical health, and to strive to maintain the wellness and integrity of their physical health.

I'm very motivated to be physically healthy.

I'm strongly motivated to devote time and effort to my physical health.

26. I have a strong desire to keep myself physically healthy.

36. It's really important to me that I keep myself in proper physical health.

46. I strive to keep myself in tip-top physical shape.

7. Health Internal Control: The items on the Internal Health Control (IHC) subscale refer to people’s belief that their health status is determined by their own personal control. More specifically, these items were designed to measure people's expectation that they themselves can exert an influence on their health. People who endorse these items are those who believe that they can determine whether their physical health is positive or negative.

7. I feel like my physical health is something that I myself am in charge of.

17. My health is something that I alone am responsible for.

27. The status of my physical health is determined largely by what I do (and don't do).

37. What happens to my physical health is my own doing.

Being in good physical health is a matter of my own ability and effort.

8. Health External Control: The items on the External Health Control (EHC) subscale refer to people's belief that their health status is determined by experiences and influences outside of their personal control. More specifically, these items were designed to measure people's expectation that their health status is largely determined by forces which they themselves can neither anticipate nor influence. People who endorse these items are those who believe that their health is not controlled by themselves rather that their physical health is under the influence of factors external to themselves.

8. The status of my physical health is determined mostly by chance happenings.

18. The status of my physical health is controlled by accidental happenings.

28. Being in good physical health is just a matter of luck.

38. Being in excellent physical shape has little or nothing to do with luck. (R)

48. I don't believe that chance or luck play any role in the status of my physical health. (R)

9. Health Expectations: The items on the Health Expectations (HE) subscale refer to an expectation that one will continue to experience positive physical health in the future. More specifically, these items were designed to measure people's belief that their health will continue to be excellent and robust. People who endorse these items anticipate that their future physical health will continue to be good.

9. I expect that my health will be excellent in the future.

19. I believe that the future status of my physical health will be positive.

29. I do not expect to suffer health problems in the future.

39. I will probably experience a number of health problems in the future. (R)

49. I anticipate that my physical health will deteriorate in the future. (R)

10. Health Status: The items on the Health Status (HS) subscale concerns people's assessment of the physical status of their body. More specifically, these items were designed to measure the extent to which people as- 
sess their body as being in excellent and robust health. People who endorse these items believe that they are in excellent physical health.

10. I am in good physical health.

20. My body is in good physical shape.

30. I am a well-exercised person.

40. My body needs a lot of work in be in excellent physical shape. (R)

50. My physical health is in need of attention. (R)

The Development and Validation of the Health Orientation Scale:

A Measure of Personality Tendencies Associated with Health

\section{Abstract}

In recent years a number of investigators have begun to examine the impact of people's personality tendencies on their physical health. The present investigation sought to further explore this issue through the development and validation of an objective self-report instrument designed to measure multiple aspects of people's health-related personality tendencies. Reliability analyses provided evidence of internal consistency for the subscales on the Health Orientation Scale (HOS). Other results indicated that both gender and age jointly influenced people's responses to the Health Orientation Scale. A final set of results revealed that the personality variables measured by the Health Orientation Scale were predictive of women's and men's compliance with actual health-promoting behaviors. The discussion focuses on the potential uses of the Health Orientation Scale in both research and applied settings.

\section{Discussion}

The purpose of the present investigation was to construct and validate an objective self-report measure of several health-related personality features: private health consciousness, defined as the tendency to be highly aware of and to think about one's physical health-fitness; health image concern, defined as the tendency to be highly aware of the external, observable impression that one's physical health makes on others; health anxiety, defined as the tendency to be anxious and nervous about one's physical health-fitness; health esteem-confidence, defined as a generalized tendency to positively evaluate and to feel confident about one's physical health; motivation to avoid unhealthiness, defined as the motivation and desire to avoid being in a state of unhealthiness; motivation for healthiness, defined as the motivational tendency and desire to keep oneself in great physical health; internal health control, defined as the tendency to believe that one's physical health and fitness is a direct function of one's own behaviors and actions; external health control, defined as the tendency to believe that one's health status is determined by uncontrollable factors factors external to oneself; health expectations, defined as the tendency to expect that one's health will be excellent and positive in the future; and health status, defined as the tendency to regard oneself as being currently well-exercised and in good physical shape. The measurement of these health-related personality tendencies was accomplished through the development of the Health Orientation Scale (HOS).

Reliability analyses confirmed that all ten subscales on the Health Orientation Scale possessed clearly acceptable levels of internal reliability. Additional findings indicated that men reported more internal health control than did women, and that they also tended to report higher scores on the health esteem-confidence and health status subscales than women. This indicates that the men in the present study believed they had more personal control of their physical health-fitness than did the women. In addition, the men in the present study tended to derive a greater sense of esteem from their physical health than did the women, and they tended to report being in better physical health. Several age related finding were also reported in this investigation. Older individuals expressed less concern than did younger and middle-age individuals about the public impression which their physical health creates. In addition, older individuals reported less anxiety about their physical health and less motivation for healthiness than did both younger and middle-age people. These findings corroborate earlier evidence reported by Bausell (1986) that there is a need for health promotion activities among older persons. Age was also found to interact with gender in predicting people's scores on the Health Orientation Scale (HOS). Middle-age males and older females expressed the strongest belief that their physical health was predominantly influenced by factors external to their own personal control.

Future research is needed, however, to clearly understand the nature of this finding. Middle-age males, for example, may be spending so much time and effort at career development that it interferes with the promotion of their physical health — and thus they develop an external locus of control orientation toward their physical health. In addition, older males may have already established themselves in their careers or else they may have already 
retired from their jobs, with the result that excessive career dedication no longer fosters an external orientation toward the control of their physical health. Certainly these are interesting ideas that need to be investigated in future work that focuses on both working men and women. Two other age related findings were found among the men and women examined in the present research. Among males, those who were younger reported the greatest motivation for healthiness and the greatest motivation to avoid unhealthiness. These young males may have reported this health motivation because of an interest in attracting members of the other gender through a healthy physical appearance. Whatever the true explanation, this finding underscores the need for greater health promotion among middle-age and older males, both of whom seemed to be the least interested in the maintenance of their physical health. Interestingly, middle-age women also reported a high level of motivation for healthiness and a high level of motivation to avoid unhealthiness, suggesting that younger and older women are especially in need of information about their physical health. Perhaps middle-age women are more knowledgeable about behaviors that contribute to physical health and thus they are more motivated to take care of themselves. Alternatively, it could be that as women approach middle-age they become more concerned about their physical appearance and the physiological implications of the aging process itself, which in turn could lead to greater motivation for healthiness and greater motivation to avoid unhealthiness. While these explanations seem possible, still future research is needed to more closely examine their plausibility.

The present investigation also provided evidence for the validity for the subscales on the Health Orientation Scale. Both men and women who reported higher scores on the motivation for healthiness and the motivation to avoid unhealthiness subscales were found to engage in a wide variety of dietary and life-style behaviors that contribute to good physical health and fitness. Further evidence for the validity of the Health Orientation Scale was indicated by the findings that internal health control was positively associated and that external health control was negatively associated with compliance to a number of health-seeking behaviors. These findings are consistent with those found for the Multidimensional Health Locus of Control Scales (Wallston, Wallston, \& DeVellis, 1978). People who believe that they themselves are the primary determinants of their health status are more likely to take control of their life in a way that contributes to the avoidance of health risks and to the promotion of health sustaining behaviors. For example, in the present investigation both men and women who had an internal health control orientation reported that they watched their weight and exercised in a routine fashion. These findings provide clear evidence that the study of the psychological tendencies assessed by the Health Orientation Scale can add to our understanding of the determinants of healthy behaviors.

Permission is granted to individuals to use the Health Orientation Scale (HOS) for research purposes. Permission granted by William E. Snell, Jr. on February 18, 1997.

\begin{tabular}{cc}
\hline Return to Dr. Snell's homepage.] & $\begin{array}{c}\text { Department of Psychology, } \\
\text { SE Missouri State University }\end{array}$ \\
$\begin{array}{c}\text { Send comments and inquires to: } \\
\text { wesnell@semovm.semo.edu }\end{array}$ & $\begin{array}{c}\text { Copyright @ 1998 } \\
\text { William E. Snell, Jr. All rights reserved. } \\
\text { This site was last updated on June 17, 2007 }\end{array}$ \\
\hline
\end{tabular}

\section{Appendix 2}

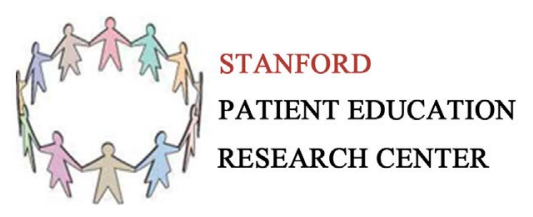

\section{Chronic Disease Self-Efficacy Scales}

We would like to know how confident you are in doing certain activities. For each of the following questions, please choose the number that corresponds to your confidence that you can do the tasks regularly at the present time.

1. How confident are you that you can keep the fatigue caused by your disease from interfering with the things you want to do?
$\begin{array}{llllllllllllll}\text { Not at all confident } & 1 & 2 & 3 & 4 & 5 & 6 & 7 & 8 & 9 & 10 & \text { Totally confident }\end{array}$


Scales/Items (using the same format as above):

Self-Efficacy to Perform Self-Management Behaviors

Exercise Regularly Scale

1. How confident are you that you can do gentle exercises for muscle strength and flexibility three to four times per week (range of motion, using weights, etc.)?

2. How confident are you that you can do aerobic exercise such as walking, swimming, or bicycling three to four times each week?

3. How confident are you that you can exercise without making symptoms worse?

Get Information About Disease Item

1. How confident are you that you can get information about your disease from community resources?

Obtain Help from Community, Family, Friends Scale

1. How confident are you that you can get family and friends to help you with the things you need (such as household chores like shopping, cooking, or transport)?

2. How confident are you that you can get emotional support from friends and family (such as listening or talking over your problems)?

3. How confident are you that you can get emotional support from resources other than friends or family, if needed?

4. How confident are you that you can get help with your daily tasks (such as housecleaning, yard work, meals, or personal hygiene) from resources other than friends or family, if needed?

\section{Communicate With Physician Scale}

1. How confident are you that you can ask your doctor things about your illness that concerns you?

2. How confident are you that you can discuss openly with your doctor any personal problems that may be related to your illness?

3. How confident are you that you can get work out differences with your doctor when they arise?

\section{General Self-Efficacy}

Manage Disease in General Scale

1. Having an illness often means doing different tasks and activities to manage your condition. How confident are you that you can do all the things necessary to manage your condition on a regular basis?

2. How confident are you that you can judge when the changes in your illness mean you should visit a doctor?

3. How confident are you that you can do the different tasks and activities needed to manage your health condition so as to reduce your need to see a doctor?

4. How confident are you that you can reduce the emotional distress caused by your health condition so that it does not affect your everyday life?

5. How confident are you that you can do things other than just taking medication to reduce how much your illness affects your everyday life?

\section{Self-Efficacy to Achieve Outcomes}

\section{Do Chores Scale}

1. How confident are you that you can complete your household chores, such as vacuuming and yard work, despite your health problems?

2. How confident are you that you can get your errands done despite your health problems?

3. How confident are you that you can get your shopping done despite your health problems?

Social/Recreational Activities Scale

1. How confident are you that you can continue to do your hobbies and recreation?

2. How confident are you that you can continue to do the things you like to do with friends and family (such as social visits and recreation)?

Manage Symptoms Scale

1. How confident are you that you can reduce your physical discomfort or pain?

2. How confident are you that you can keep the fatigue caused by your disease from interfering with the things you want to do?

3. How confident are you that you can keep the physical discomfort or pain of your disease from interfering with the things you want to do?

4. How confident are you that you can keep any other symptoms or health problems you have from interfering with the things you want to do? 
5. How confident are you that you can control any symptoms or health problems you have so that they don't interfere with the things you want to do?

a) Manage Shortness of Breath Item

1. How confident are you that you can keep your shortness of breath from interfering with what you want to do? Control/Manage Depression Scale

1. How confident are you that you can keep from getting discouraged when nothing you do seems to make any difference?

2. How confident are you that you can keep from feeling sad or down in the dumps?

3. How confident are you that you can keep yourself from feeling lonely?

4. How confident are you that you can do something to make yourself feel better when you are feeling lonely?

5. How confident are you that you can do something to make yourself feel better when you are feeling discouraged?

6. How confident are you that you can do something to make yourself feel better when you feel sad or down in the dumps?

\section{Scoring}

The score for each item is the number circled. If two consecutive numbers are circled, code the lower number (less self-efficacy). If the numbers are not consecutive, do not score the item. The score for each scale is the mean of the items. For scales of 1 - 2 items, do not score the scale if any item is missing; for scales with 3-4 items, do not score the scale if more than 1 item is missing; for scales with 5 - 6 items, do not score the scale if more than 2 items are missing. Higher number indicates higher self-efficacy.

\section{Characteristics}

\begin{tabular}{|c|c|c|c|c|c|c|c|}
\hline Scale & $\begin{array}{c}\text { No. of } \\
\text { Subjects }\end{array}$ & $\begin{array}{l}\text { No. of } \\
\text { items }\end{array}$ & $\begin{array}{c}\text { Observed } \\
\text { Range }\end{array}$ & Mean & $\begin{array}{l}\text { Standard } \\
\text { Deviation }\end{array}$ & $\begin{array}{l}\text { Internal } \\
\text { Consistency } \\
\text { Reliability }\end{array}$ & $\begin{array}{l}\text { Test-Retest } \\
\text { Reliability }\end{array}$ \\
\hline Exercise regularly & 478 & 3 & $1-10$ & 6.30 & 2.70 & 0.83 & 0.86 \\
\hline Get information on disease & 478 & 1 & $1-10$ & 7.37 & 2.65 & - & 0.72 \\
\hline Obtain help from community, family, friends & 478 & 4 & $1-10$ & 6.18 & 2.42 & 0.77 & 0.85 \\
\hline Communication with physician & 477 & 3 & $1-10$ & 7.30 & 2.71 & 0.90 & 0.88 \\
\hline Manage disease in general & 292 & 5 & $1-10$ & 6.92 & 2.15 & 0.87 & - \\
\hline Do chores & 478 & 3 & $1-10$ & 6.29 & 2.70 & 0.91 & 0.86 \\
\hline Do social/recreational activities & 478 & 2 & $1-10$ & 6.50 & 2.65 & 0.82 & 0.84 \\
\hline Manage symptoms & 478 & 4 & $1-10$ & 5.88 & 2.40 & 0.91 & 0.89 \\
\hline $\begin{array}{l}\text { Manage shortness of breath } \\
\text { (only reported on those reporting } \\
\text { shortness of breath) }\end{array}$ & 280 & 1 & $1-10$ & 5.87 & 2.97 & - & 0.82 \\
\hline Control/manage depression & 478 & 6 & $1-10$ & 6.51 & 2.23 & 0.92 & 0.82 \\
\hline
\end{tabular}

\section{Source of Psychometric Data}

Stanford Chronic Disease Self-Management Study. Psychometrics reported in: Lorig, K., Stewart, A., Ritter, P., González, V., Laurent, D. and Lynch, J. (1996) Outcome Measures for Health Education and other Health Care Interventions. Sage Publications, Thousand Oaks, 24-25, 41-45.

\section{Comments}

These scales were developed and tested for the Chronic Disease Self-Management study. We use a shorter, 6-item scale now, as it is much less burdensome for subjects.

\section{References}

Lorig, K., Stewart, A., Ritter, P., González, V., Laurent, D. and Lynch, J. (1996) Outcome Measures for Health Education and other Health Care Interventions. Sage Publications, Thousand Oaks, 24-25, 41-45.

To download this scale and scoring instructions, right click the link below with your mouse and "Save as" to you hard disk or desktop (for Windows), or double click (Mac). 